\title{
Didáctica de la danza tradicional para la escuela: revisión bibliográfica Traditional dance didactics for the school: bibliographic review
}

\author{
Raquel Pastor Prada, Ángela Morales Fernández \\ Universidad Autónoma de Madrid (España)
}

\begin{abstract}
Resumen. Este artículo se propone una revisión bibliográfica con el objetivo de determinar qué publicaciones existen sobre una didáctica específica de las danzas tradicionales o folclóricas (de Españay del mundo) parala escuela, así como analizar cada una de estas referencias respecto a los conceptos metodológicos que ofrece. Nuestra intención en este sentido sería poder establecer si las nuevas formas de entender los procesos de enseñanza-aprendizaje se han visto reflejadas en estos contenidos escolares para esbozar la evolución en aspectos de innovación educativa y renovación pedagógica que ofrecen para el aula. Esta revisión bibliográfica, supone desde nuestro estudio, mostrar una foto fija de los material es con los que cuentan los docentes, junto con la descripción y presentación de cada uno de los documentos encontrados y anal izados. Finalmente, se concluye con una reflexión sobre la pertinente publicación actual izada de nuevos paradigmas en la enseñanza de la danza tradicional para la escuela.
\end{abstract}

Palabras clave. Folclore; Danza tradicional; Escuela; M etodología y Didáctica específica.

\begin{abstract}
This article proposes a bibliographical review with the aim of determining what publications exist on a specific didactics of traditional or folk dances (from Spain and the world) for the school, as well as analysing each of these references with respect to the methodological concepts it offers. 0 ur intention in this sense would be to be able to establish if the new ways of understanding the processes of teaching-learning have been reflected in these school contents to outline the evolution in aspects of educational innovation and pedagogical renovation that they offer for the classroom. This bibliographical review supposes, from our study, to show a still picture of the materials available to the teachers, together with the description and presentation of each one of the found and analysed documents. Finally, it concludes with a reflection on the relevant updated publication of new paradigms in the teaching of traditional dance for the school.
\end{abstract}

Key words. Folklore; Traditional Dance; School; M ethodology and specific didactics.

\section{Introducción}

Desde los años setenta, nuestro país ha venido asistiendo a la implementación de diferentes Leyes Educa tivas en las que, de una u otra manera, y con más 0 menos presencia, la Educación Musical forma parte de las diferentes propuestas curriculares tanto para la Educación Primaria como para la Educación Secundaria. Ya en la Ley 14/ 1970 General de Educación y Financiamiento de la ReformaEducativa (LGE), se contemplaba el área de Expresión Dinámica en la Educa ción Primaria, que englobaba la educación del movimiento, ritmo, expresión corporal, mimo, dramatiza ción, juegos, gimnasia, deportes, música, etc. , entreotros contenidos.

La siguiente Ley de Educación, la LOGSE (Ley O rgánica de O rdenación General del Sistema Educativo), del 3 de octubre de 1990, contemplaba un área de Expresión Artística (integrada por M úsica, Plástica y Dra

Fecha recepción: 22-07-20. Fecha de aceptación: 28-11-20

Raquel Pastor Prada

raquel.pastor@uam.es matización), en la que se incluyeron entre otros contenidos, El lenguaje corporal, El juego dramático, Artes y cultura, así como aspectos destacados del patrimonio cultural propio y de otras culturas.

En 2006, se aprueba la LO E (Ley 0 rgánica de Educación) y en 2013 la LOMCE (Ley O rgánica para la M ejora de la Calidad Educativa), ésta última vigente hasta este 2020. En ellas se incluyen tanto contenidos, como objetivos y competencias que hacen referencia de forma explícita al área de movimiento, a las danzas, y otras manifestaciones artísticas del patrimonio cultural propio y de otros pueblos.

Ilustra este breve recorrido legislativo y los apuntes someros expuestos, que, en el área de Educación Artística, la Educación Musical incluye el bloque de contenidos de Movimiento y Danza ligado al folclore, tanto referido al patrimonio español como al de otras culturas. Es un hecho que la revolución metodológica desde los años setenta hasta nuestros días es una realidad en evolución constante en nuestro país, sin embargo, las nuevas formas de entender los procesos de enseñanzaaprendizaje no se han visto reflejados en la necesaria y progresiva innovación que se hubiera requerido para todas las áreas, tal es el caso que nos ocupa, la enseñanza 
de las danzas tradicionales en las aulas de Educación Primaria y Secundaria (Díaz, 2017, 2018), que por otra parte compartimos con el área de Educación Física, en las materias de Expresión Corporal (López, López \& Vicente, 2020).

Muchas son las preguntas que surgen de forma general a nivel educativo, y de forma concreta con la Educación M usical y la presencia del folclore en las aulas, más aún sobre la presencia de las danzas folclóricas de nuestro país y del mundo y, sobre todo, la formación, adecuación y evolución metodológica y didáctica del profesorado especialista, y la literatura que de estos aspectos existe.

Algunos estudios postulan que los conocimientos respecto a la danza en la educación no suelen ser muy amplios en la formación inicial de maestros de música, (Díaz, 2012; Domínguez, 2012; Herrera, 2000; Lago \& Espejo, 2007; López \&Vicente, 2019) y que tales conocimientos, solo pueden ser adquiridos mediante la práctica real (Ríos, 2017) y laconsideración del cuerpo como experiencia para la expresión y la comunicación creativa dentro de una educación corporeizada (Águila, 2019; Prados, 2020). Q ueremos incidir en la dificultad añadida que supone la escasez de estudios y publicaciones al respecto (Díaz, 2012; Peña \& Vicente, 2019), no solo referentes a posibles materiales y repertorios, sino especialmente a investigaciones que aborden las metodologías y didácticas específicas para su aplicación en las aulas. Es por ello que, se hace necesaria la creación de un espacio de reflexión sobre la diversidad y plasticidad metodológica que presenta la danza en la escuela, dada su naturaleza transversal e interdisciplinar, con el fin de sistematizar las acciones, actividades, procedimientos y contenidos de proyectos educativos relativos a la danza (Aguilera, 2016). Este artículo se propone una revisión bibliográfica con el objetivo de determinar qué publicaciones existen sobre una didáctica específica de las danzas tradicionales o folclóricas (de España y del mundo) para la escuela, así como analizar cada una de estas referencias respecto a los conceptos metodológicos que ofrece.

\section{Las danzas tradicionales en el aula}

En este escenario, Muela \& Señor (1997) defienden que las danzas folclóricas o tradicionales son un medio adecuado para introducir al alumnado en el ámbito del movimiento, ya que, además de toda la simbología y tradición que nos revelan, son asequibles, no requieren de una preparación física especial y contribuyen de forma lúdica a un importante trabajo psicomotriz en rela ción al uso del espacio y el tiempo, al conocimiento y la expresión sin prejuicios de nuestra propia expresividad y a la relación con nuestros iguales. Las danzas tradicionales tienen algo de verdad profunda, de honesta autenticidad, nos conectan con nuestras raíces antropológicas $y$, en ello, reside el sentimiento de fuerte conexión interior y colectiva que establecemos al bailarlas, ya sea mos bailarines experimentados 0 inexpertos. En este sentido, y sobreel concepto de actividad grupal, M aschat (2006) relata cómo a lo largo de todos sus años de experiencia ofreciendo sesiones de introducción a las danzas tradicionales, ha observado la fascinación que ejerce la danza coral (término acuñado por la autora) en las personas.

Grupos homogéneos [... ] y heterogéneos [... ] responden por igual a los impulsos de la música, del ritmo, de la dinámica y el carácter que sugiere, llevados de la mano de sus compañeros en un círculo 0 una línea, o moviéndose en figuras sencillas y caminos entrelazados «como por arte de magia». [... ] La danza coral con su fuerte componente social en una de las posibles formas de iniciarse en la práctica del movimiento. (pp. 7-9).

Sin embargo, las danzas tradicionales o folclóricas no se hallan incorporadas habitualmente en las aulas y su pervivencia se debe al interés personal de algunos docentes (Díaz, 2017; Vicente, M ondéjar \& Díaz, 2014; Zamora, 2002). Díaz (2012) pone el acento en que esta situación de exclusión se debe a dos motivos fundamental es: la exigua relevancia que dentro del currículo se le otorga a la danza por parte de docentes y legisladores, y la incompleta formación inicial que reciben los futuros educadores en esta materia. 0 tro aspecto que compartimos con Muela \& Señor (1997) es el miedo a un rechazo por parte del alumnado, cuando señalan que «Como en cualquier materia, si el profesor o profesora está motivado positivamente y conoce bien el tema, podrá transmitir su interés por él. Su enfoque pedagógico es fundamental para que no llegue a crear frustra ciones en el alumno 0 alumna» (p.51).

\section{La enseñanza de la danza tradicional: de lo po- pular a lo institucionalizado}

La danza tradicional o folclórica, como arte dinámica y vital, perteneciente al acervo del patrimonio cultural, ha permanecido vigente gracias a la tradición oral. Cuando pervivía en contacto directo con el pueblo, la transmisión era viva, estaba viva. La enseñanza se producía de mayores a pequeños, participando de un modo espontáneo, lúdico, aprendiendo por imitación simultá 
nea de una forma progresiva, natural y relajada, vinculada muchas veces a ambientes festivos. La figura del «maestro de baile» 0 del bastonero, también llamado birria 0 botarga, era un intermediario entre la tradición antigua y los tiempos actuales, y se ha conservado hasta la pasada guerra civil española en muchas zonas de nuestro país (Díaz \& Porro, 2007). Normalmente, era ostentada por un músico o danzante experimentado, que conocía tan perfectamente el baile antiguo que podía hacerlo llegar «a las generaciones siguientes con la mínima distorsión, tal y como a él le había sido entrega do» (Díaz \& Porro, 2008, p.41).

H aselbach (1979) describe cómo ha evolucionado el aprendizaje de la danza en ámbitos populares, afirmando que hasta el siglo pasado la danza fue independiente de la enseñanza institucionalizada. Durante siglos las danzas ya existentes sólo se podían aprenden de otros. Se conocía una danza porque se presenciaba, se compartía desde la práctica y se aprendía, sin que de ello surgiera una verdadera reflexión sobre la didáctica empleada. A partir del último tercio del siglo XX las cosas cambian, los usos y costumbres tradicionales se ven desplazados y la forma no organizada y natural de transmisión de bailes y danzas se reduce. La danza se integra como acción pedagógica en ámbitos escolares y extraescolares y, con ello, comienza la necesidad, y también la responsabilidad, de planificar una didáctica de la danza en el terreno de la enseñanza amateur.

La didáctica de la danza popular, preferentemente reservada a lo largo de la historia a ámbitos de educa ción informal, debe adaptarse, no sin dificultades, a las circunstancias de una educación reglada, sea formal o no formal, cuando a comienzos de los años setenta del siglo pasado los sistemas tradicionales de enseñanza deben adecuarse a los rápidos cambios socioeconómicos que se estaban produciendo (Haselbach, 1979). Algunos autores señalan cómo este proceso de transposición didáctica de formas y saberes expresivos, libres y vitales (no procedentes de un marco académico) implica una inevitable trasformación de los contenidos, así como el peligro de perder cualidades esenciales como la espontaneidad, la libertad de movimiento y el disfrute, la plenitud de sentidos, la función social o el sentido de construcción identitaria(Fontán, 2019; H aselbach, 1979; Vitanzi, 2015).

En todos estos años de aprendizaje en diferentes países y regiones me he encontrado con una única forma de transmisión, la de copiar el movimiento hasta que lo cojas (o no), es decir la total ausencia de método. Sin duda la imitación del modelo es el ins- trumento más eficaz en cuanto a la captación de la postura, la fluidez del movimiento y del estilo, pero el camino hacia el conocimiento y la apreciación en mucho más amplio. (Maschat, 2001, p.47)

No es preciso nombrar los beneficios que la danza, también la tradicional, puede aportar al desarrollo integral del alumnado. Sin embargo, quizás se hace necesario recordar la importancia de reflexionar sobre procesos metodológicos y didácticos que sean coherentes y refuercen estos elementos de valor: el carácter lúdico, artístico y social del baile y la danza tradicional de los pueblos, que puede contribuir a la relación con nuestros semejantes a través de un lenguaje corporal, no verbal y sensorio-emocional, la cimentación de la propia identidad a través de nuestro movimiento y gestualidad individual, la contribución al autoconocimiento, ala construcción de un sentimiento de pertenencia a una comunidad, de cohesión social, en el que somos comprendidos y comprendemos la diferencia del otro, la diversidad individual y cultural (Díaz, 2012, 2017; M artín, 2005; Matos-Duarte, Smith \& Muñoz, 2020; Vicente, et al., 2014). «En lo referente a la danza tradicional, en especial las danzas juego y las infantiles, [... ] una metodología bien orientada, puede incidir o ayudar en el desarroIlo integral y diversificado de los/ as niños/ as que las practican» (Larrinaga, 2007, p. 362).

Entendemosque, paraincorporar un repertorio tradicional de danzas en la Educación Infantil, Primaria y Secundaria, así como en otros contextos no reglados 0 extraescolares (educativos, socioculturales o comunitarios), es necesario atender a otras formas de abordar, de transmitir y de enseñar, para favorecer el aprendiza je y valores educativos de comunicación, expresión y relación entre iguales. De este modo, se hace necesaria una didáctica específica, como en el resto de las áreas curriculares, en este caso, vinculada a la educación musical, y acorde con las renovacionespedagógicas de nuestra época. Aquel personaje del birria o botarga, personificado en el docente actual, no solo debe atender a la transmisión rigurosa de la tradición, como era su cometido en tiempos antiguos, sino que debe de velar por un proceso educativo que fomente el desarrollo social, emocional, cognitivo, psicomotriz, expresivo, creativo y comunicativo del alumnado, es decir, por su desarroIlo integral a través de la educación artística y estética.

\section{Materiales y metodología}

El corpus documental sobre el que se ha elaborado esta revisión bibliográfica, se estructura en tres ejes, 
integrados en los objetivos propuestos en esta investigación:

1. Revisar las publicaciones educativas en nuestro país disponibles para el profesorado de las enseñanzas generales obligatorias en los siguientes ámbitos temáticos:

\section{El folclore y la escuela.}

El repertorio de danzas tradicionales españolas y del mundo.

Metodología y escuela (experiencias, procesos metodológicos y didácticos) en relación con las danzas folclóricas.

En la clasificación de los materiales encontrados (libros, capítulos de libro y artículos fundamentalmente), podíamos haber atendido al aspecto que más define la evolución sobre publicaciones y procesos de enseñanzaaprendizaje, unacatalogación cronológica, si bien, y atendiendo en todo momento a las tres categorías definidas, éstas estructuran finalmente la ubicación de cada elemento bibliográfico revisado.

2. Analizar el material bibliográfico, motivo de la revisión, definiendo las variables pedagógicas significativas, como determinantes en la evolución de las diferentes publicaciones encontradas.

A la hora de analizar los documentos, hemos definido una serie de variables y el aborado una ficha de trabajo para cada uno de los textos. Se centran fundamentalmente en: autor, año de edición, aspectos reseñables en cada una de las tres categorías que acabamos de definir, que iremos exponiendo en forma de ensayo. Por otra parte, en el análisis, se han tenido en cuenta cada una de las ideas expuestas en los textos que justifiquen el qué (repertorio) y el porqué de las danzas tradicionales en el ámbito educativo (o viceversa) y el cómo llevar a cabo dichalabor, resaltando los procesos metodológicos y didácticos particularmente significativos que nos aporten los diferentes autores, que definan una hoja de ruta en la enseñanza de las danzas a los docentes, como soporte formativo didáctico.

Para la selección del corpus documental se han tenido en cuenta dos criterios fundamentales que responden a la temática general, la danza tradicional y su didáctica en las enseñanzas de régimen general y su proyección y elaboración de propuestas pedagógicas para los docentes. O tro de los criterios fundamentales ha sido la elección de publicaciones españolas.

\section{Análisis y revisión bibliográfica}

\section{El foldore y la escuela}

Desde hace décadas se viene advirtiendo la progresiva desaparición de la cul tura tradicional en las socieda desactuales(Álamo, 1994; Larrea, 1950; Sciacca, 1965), así como el distanciamiento respecto ala danzafolclórica y su significación social, expresiva y comunicativa por diferentes motivos, como la pérdida del carácter ritual del baile como medio de adoración y veneración, la tendencia actual al individual ismo en nuestras ciudades, el éxodo rural, las circunstancias socio-políticas, ladesapa rición de los oficios tradicionales, el auge de los medios audiovisuales o la estandarización impuesta por los massmedia (Díaz \& Porro, 2007; H aselbach, 1979; Larrinaga, 2007; Maschat, 2006; Vicente, et al., 2014; Zamora, 2002).

Desde los años cincuenta del pasado siglo, encontra mos documentos que inciden en la importancia del folclore dentro de la práctica docente y de una didáctica folclórica que conecte la escuela con la cultura tradicional que el niño ${ }^{1}$ vive en su cotidianeidad (Larrea, 1950; Moya, 1956; Sciacca, 1965), revisando las relaciones entre el niño y el folclore y la responsabilidad de los educadores en la proyección didáctica de las actividades folclóricas (Larrea, 1958; Sciacca, 1965; Torner, 1965). En estos tiempos se defendía el folclore como una herramienta que se ofrece al maestro rural para conectar con las influencias tradicionales que los niños ya poseen al llegar a las aulas, incorporándole a la tarea de la investigación folclórica para su aprovechamiento educativo (Larrea, 1958). A su vez, ya por entonces se sostiene la importancia de estudiar el folclore por hallarse ignorado en su mayor parte y se entiende la necesidad de concebir la «escuela como centro colector y divulgador etnográfico» (Larrea, 1950, p.29), señalando las venta jas de trabajar las formas tradicionales con un enfoque transversal en conexión con el resto de disciplinas escolares (Larrea, 1950; M oya, 1956), capaz de despertar la curiosidad intelectual y creativa de los niños (Torner, 1965) y como elemento motivador y de conocimiento y comprensión de otras formas de vida y de pensamiento (Colomer, 1979).

Larrea (1958) habla específicamente de la importancia social de la danza y su aportación eficaz a la formación integral del niño, a pesar de su inexistencia en la escuela. Además, defiende la danza popular frente a la llamada Gimnasia rítmica de la época, atendiendo a las ventajas que bajo su criterio presenta: (a) el niño está familiarizado con ella a través de los juegos de rueda, (b) la ha vivido en su propio contexto y (c) constituye un «elemento de relación social de la mayor importancia» (p. 149). 
En la última década del siglo XX, Álamo (1994) invita a «reavivar el rescoldo de formas de la tradición a punto de desaparecer» (p.12), y defiende la importancia de incidir en la percepción y la sensibilización del profesorado hacia estos temas y de la responsabilidad de todos los agentes de la comunidad educativa para su implementación. Las instituciones educativas pueden aportar y sumar al folclore y no solo recibir del mismo. Abrir las puertas de la escuela a las diversas manifesta ciones del folclore (canciones, danzas, juegos, cuentos, leyendas) debe y puede contribuir a su revitalización, y no solo a su conservación y transmisión.

Por otro lado, las nuevas metodologías en educación musical surgidas en la primera mitad del siglo XX dentro de un contexto social para la recuperación y acepta ción del folclore tradicional, desarrollaron una importante labor para la inclusión de este repertorio en la escuela, constituyendo para la pedagogía del momento una gran innovación que en nuestros días debería ser revisada para darle una nueva realidad (A révalo, 2009). Algunas de ellas, como la metodología 0 rff-Schulwerk, defienden la inclusión de la danza tradicional en el aula combinada junto al lenguaje y la música, tal y como en todas las culturas ocurre. Sin embargo, estas ideas no fueron fielmente reflejadas en las primeras publicaciones escritas y radiofónicas que difundieron esta metodología a partir de 1948, debido a la inexistencia de un formato gráfico paralanotación y transmisión de ladanza (Haselbach, 2011), lo cual nos hace pensar en las dificultades que supone este hecho para su adecuada implementación en las aulas.

En la década final del siglo XX en nuestro país, apa recen publicaciones didácticas con una manifiesta intencionalidad de revalorizar lo tradicional, recuperando cancioneros del folclore infantil y juegos populares, debido a circunstancias coyunturales entre las que desta can el desarrollo del currículo de la LO GSE (1990), la profesionalización y los procesos de construcción identitaria. Se abren nuevas líneas de trabajo que superan un modelo educativo marcadamente etnocentrista, en el que solo la música de tradición culta era incluida en el aula (Costa, 1997). También encontramos alguna iniciativa interesante para estructurar y ordenar los estudios del folclore dentro de la escuela, atendiendo alos diversos elementos didácticos que debe contemplar la planificación docente(principioseducativos, justificación, motivaciones y val ores, objetivos, contenidos, metodología, actividades, temporalización y evaluación), si bien vinculados a las diferentes materias troncales del currículo (Puras, Rivas \& Zamora, 1996). Sin embargo, pese a los esfuerzos realizados, este tipo de repertorio sufrirá un notable retroceso con la entrada del siglo XXI, y se reclama la necesidad de impulsar la reflexión e investigación docente para revitalizar la práctica del foIklore en las aulas desde un enfoque didáctico (A révalo, 2009).

\section{El repertorio de danzas tradicionales españo- las y del mundo}

Esta categoría es la más extensa, conformada por publicaciones que muestran principalmente la recopilación de un repertorio tradicional de danzas adecuadas y asequibles a la escuela, en sus diferentes etapas y ciclos, existiendo en muchas de ellas un esfuerzo importante y nada desdeñable por enriquecer este reper torio con una valiosa información sobre la contextualización social y cultural de las danzas aportadas, músicas e instrumentos tradicionales, trajes, usos y costumbres, etc. (Cancelas, Jurado \& Sampil, 2013; Dekker, 2015; Espejo, 1999; Fernández, 1999; Fuertes, 1993, 2006; Fuertes\& Zamora, 1996; López-Ibor \& M aschat, 2006; 0 ssa, Iglesias, Fügedi \& Parga, 2009; Pedeslán, 2010; Pereira \& Prieto, 2010; Puras, et al., 1996; Sánchez \& Martín, 2002; Zamora, 1995, 2002). Si bien encontramos en ellas actividades introductorias, así como indicaciones precisas sobre los aspectos psicomotrices y musicales a desarrollar en cada una de las coreografías, e incluso propuestas metodológicas sobre secuenciación de las sesiones y elaboración de versiones de una misma danza según diferentes grados de dificultad (Renobell, 2009), estos apartados no son muy extensos ni profundizan reflexivamente en las orientaciones que se ofrecen sobre los procesos didácticos.

Estas publicaciones defienden los valores formativos, pedagógicos, culturales, psicomotrices y lúdicos de la danza tradicional, y la implicación de los agentes sociales y educativos para su desarrollo. Destacan las edita das en las comunidades del norte de nuestra geografía, con mayor recorrido en losestudios folclóricos (Larrea, 1958), que, a partir de la constitución del estado de las autonomías, seven inmersas en la búsqueda de una identidad común y propia, diversificada y diferenciada, através de su patrimonio cultural recogido, adaptado o elaborado, difundido y utilizado en el marco educacional, en el que la danza se concibe como agente dinamizador de identidad social. Estas propuestas se alejan de la visión de folclore uniforme, colorista e infantilizado que, a veces, se ubica en fiestas «masificadas e individualistas, inclinadas al espectáculo y a su comercialización» (Larrinaga, 2007, p. 366), y defienden la incorporación 
de la danza popular a los aprendizajes escolares como elemento que, más allá del aspecto festivo, es fundamental y transversal en el desarrollo integral de niños y niñas (Sac de Danses, El, 1994). Destacan la importancia de la danza en el juego espontáneo, en los procesos de participación, cooperación y relación natural entre ambossexos, así como en el protagonismo del alumnado dentro del aprendizaje (Patricio, 2018).

\section{Metodología y escuela (experiencias, procesos metodológicos y didácticos) en relación con las dan- zas folclóricas}

En la tercera categoría, ubicamos aquellas publica ciones y estudios que describen experiencias concretas desarrolladas con danzas tradicionales en el aula y otras publicaciones que aportan propuestas metodológicas y didácticas para la enseñanza de las danzas folclóricas. Hay que destacar publicaciones científicas recientes que, si bien no abordan con detalle los procesosmetodológicos y didácticos, objeto de estudio del presente artículo, describen experiencias educativas en torno a la danza tradicional, con resultados altamente positivos respecto a la aceptación, valoración y disfrute de los al umnos ha cia este tipo de repertorio (Arias, Fernández $\&$ San Emeterio, 2020; Díaz, 2012; Gillanders, Rodríguez \& Eirín, 2019; Matos-Duarte, et al., 2020; Vicente, et al., 2014).

Respecto a los principios educativos, reseñamos como primera premisa la que nos aporta Larrinaga (2007) quien relaciona la danza folclórica con «el desa rrollo integral del niño o niña, mediante el uso adecua do que nos ofrece el Folclore infantil (actitudes, procedimientos y conocimientos)» (p.372), determinante en el desarrollo estético y cultural (Haselbach, 1979; Maschat, 2006).

La selección de un repertorio adecuado y adaptado a cada situación pedagógica es fundamental en la misma medida que una buena didáctica que contemple aspectos de inclusión social y desarrollo de lacreatividad (Díaz, 2017; H aselbach, 1979; M aschat, 2001; Vitanzi, 2015). Debemos de incidir en el uso de la danza tradicional en el aula como un medio, no como un fin (Díaz, 2017; Haselbach, 1979; Larraz, 1988), en la importancia del proceso frente al resultado, planificando no solo qué vamos a enseñar, sino también cómo lo vamos a hacer (proceso metodológico, que no método de enseñanza), porque es precisamente en ese proceso donde se produce el aprendizaje. Hasta los años ochenta del siglo pasado, toda enseñanza ha estado más orientada al producto que al proceso de obtención y, sin embargo, cuan- do en el ámbito de la didáctica de la danza hablamos del concepto danza, éste abarca tanto el proceso del danzar como también su producto, es decir, una danza determinada. Este desarrollo didáctico debe ser secuenciado en diferentes fases, etapas o versiones didácticas (no se disecciona la danza, se trabaja como estructura completa), cada una de las cuales, con un grado mayor de complejidad, es decir, se suceden en pro de una interpreta ción de calidad adaptada que mantenga su carácter específico (Haselbach, 1979).

0 tra de las recomendaciones que encontramos es la utilización del círculo para iniciar la enseñanza, como formación inclusiva, en la que todos tenemos cercanía física y contacto visual (veo y soy visto) y un lugar, también simbólicamente hablando, dentro del grupo. Es por tanto una organización espacial más equitativa y cooperativa, ya que no se establecen jerarquías: todos somos iguales, el papel de cada uno es igual de importante para la consecución exitosa de la danza. Se debería romper la denominada enseñanza frontal pues ciertamente «es el modo más rápido de enseñar a los niñosuna danza o baile; pero es también el modo más parcial, más unilateral, de hacerlo» (Haselbach, 1979, p.69).

El corro siempre genera una energía especial, es «una figura en la que la dinámica de la música y del grupo «nos lleva», nos impulsa, y nos proporciona una vitalidad que se multiplica» (M aschat, 2006, p.7). Presentaal gunosinconvenientes en relación con la lateralidad y la capacidad del profesor para «controlar los defectos de ejecución con tanta rapidez como si todos los niños estuvieran colocados en filas; pero éstos, en cambio, pueden ayudar por sí mismos a sus compañeros, con lo que se fomenta la cooperación e independencia de la enseñanza» (H asel bach, 1979, p. 70).

La didáctica ciertamente es imitación. Pero la reflexión y la investigación-acción docente busca estilos de enseñanza divergentes, procesos metodológicos que se alejen de la reproducción de modelos mediante instrucción directa, del «parar, repetir, volver a explicar, y repetir» (Ereño, 2011, p.8), para no olvidar el objetivo final: disfrutar de la alegría y el placer de bailar al mismo tiempo que aprendemos (Larraz, 1988, 2003). Este aspecto parece incorporar una de las características didácticas de la transmisión tradicional, como es dar prioridad al uso de la danza y al disfrute, más que a la calidad de la ejecución. En el ámbito educativo se comprende que «el baile es correcto desde el momento que resulta divertido, que sirve para comunicarse y para relacionarse, consiguiéndose así un ambiente de juego muy constructivo» (Rizo, 1996, p. 78). 
Cuando trabajamos danzas sencillas resulta muy útil el uso de la imitación simultánea del docente, para poner en acción rápidamente a los participantes sin tiempo para reaccionar ni pensar si serán capaces de seguirnos (M aschat, 2006), sin utilizar música e incluso sin palabras (Larraz, 1988; Sac de Danses, El, 1994). En caso de danzas «más complicadas, pueden aprenderse elementos por separado, mediante la imitación visual, o también después de haber escuchado una breve y precisa explicación [... ], y, por último, construir con ello partes formales y la danza completa» (H aselbach, 1979, p.69). O tra propuesta sería hacer pequeños grupos rotatorios, tantos como partes o bloques la danza posea, para visualizar o bailar cada bloque y llegar a distinguir sus matices (Sac de Danses, El, 1994).

La imitación y la reproducción juegan un papel importante en el aprendizaje del repertorio tradicional, al igual que la improvisación y, por ello, deben ser pensadas como espacio de sensibilización y «de libertad para quien recibe esa herencia cultural y la resignifica» (Vitanzi, 2015, p.81). El desarrollar laexpresión creativa del alumnado no deja de ser un factor de sumo interés. Podemos encontrar ejemplos de danzas tradicionales de raíz histórica o etnológica, así como del repertorio infantil, con partes improvisadas en las que un líder debe inventar una variación para imitarla de forma simultá nea 0 sucesiva (en eco), «siempre respetando su música, su carácter y su procedenciacultural» (M aschat, 2006, p.8). Así mismo, resulta interesante incorporar estos elementos creativos en los procesos didácticos para que nuestros alumnos tengan la posibilidad de improvisar 0 variar (Díaz, 2017; Haselbach, 1979; Larraz, 1988)

Para iniciar la enseñanza de una danza tradicional podemos utilizar diferentes recursos: «lenguaje y textos, motivos rítmicos, líneas y frases melódicas, patrones en el suelo y en el aire, emociones, juego dramático, artes visuales» (M aschat, 2013, p. 7), cuentos, historias, leyendas, canciones y melodías, juegos, imitación simultánea, elementos propios de la danza, dramatiza ciones o conexión con otras materias, entre otros $(\mathrm{Sac}$ de Danses, El, 1994).

De estos conceptos, el más importante se centra en empezar el aprendizaje desde la música, mediante un proceso lúdico y natural, antes de acercarse a la danza de forma cognitiva 0 analítica. «El elemento fundamental es siempre la Música. La escucha con todo el cuerpo es la base para poder sentir, comprender y disfrutar de una danza» (M aschat, 2001, p.47). Como ocurría en la transmisión oral, el conocimiento técnico y pedagógico de las danzas debe ir acompañado de sus acompañamien- tos rítmicos tradicionales, con pautas metodológicas que pongan «en relación melodías, ritmos y coreografías en sus diferentes vertientes y variada casuística» (Lar rinaga, 2007, p. 371). Maschat (2013) señala diversas estrategias y propuestas, reconocer la forma musical de la danza, interiorizar los motivos rítmico-melódicos y desarrollar el sentido del pulso, el ritmo y la frase mediante acciones lúdicas de encuentro/ desencuentro, creatividad e imitación, desplazamientos, pasos básicos o figuras, con música grabada o interpretada por el docente. Haselbach (1979) también apunta diferentes posibilida des, desde la interpretación libre de la música a secuencias de pasos tomadas del original, o formas en el espa cio con diferentes agrupamientos. El colectivo catalán El Sac de Danses (1994) recomienda el aprendizaje a partir de la melodía (cantada o grabada) para trabajar la pulsación, el ritmo, la frase, la estructura musical y coreográfica, o jugando con el título de la danza vocalizándolo de forma silábica, poniéndole movimiento. 0 tros autores exponen ideas similares: García (Ríos, 2017) propone como introducción a la danzael contacto con lamelodía; Díaz (2012, 2017) introduce juegosrítmicos y de exploración libre y creativa de movimiento para trabajar elementos espaciales y musicales que posteriormente serán incorporados a la coreografía original; Martín (2005) proponeintroducir las canciones-juego del folclore infantil, al encontrar en sus movimientos naturales y evoluciones espaciales básicas una suave transición al movimiento organizado y los esquemas coreográficos de las danzastradicionales; Vitanzi (2015), aconseja superar el espacio a veces parcial y limitado de este repertorio, ofreciendo una experimentación con diferentes distancias interpersonales, así como ejercicios de descarga y traslación del peso de un pie a otro, paraintroducir pasosmás complejosen compásternario, y Larraz (1988) recomienda partir de las acciones espontáneas de cada edad, para que los discentes se sientan cómodos y capaces de hacer, para iniciar «situaciones lúdicas de búsqueda, por parte del niño, de la rela ción, cuerpo-música» (p. 16).

Estos juegos, versiones o introducciones al repertorio fomentan el aspecto social y emocional tan importante en la educación. Las danzas tradicionales son bailes colectivos donde lo importante es la cooperación: el éxito dependerá de la capacidad para realizar los movimientos coreográficos de forma coordinada con la música y con los otros, reforzando la cohesión grupal y la responsabilidad individual ante la tarea común, lo que Larraz (1988) denomina como «trabajo sociomotor: cooperativo» (p.17). «Cada individuo forma parte de 
un todo [... ], por lo que hay que medir la fuerza y la intensidad en los desplazamientos para lograr la unidad y laarmoníadel conjunto» (M uela\& Señor, 1997, p. 50). «Esta mezcla entre individualismo y comunidad genera una especie de inteligencia compartida, uniendo a los participantes, por muy heterogéneo que sea el grupo, y a la vez se enriquece con las diferencias entre ellos» (Maschat, 2006, p.8). Díaz (2012) apunta también en este sentido, postulando que son actividades que mejoran la relación entre diferentes sexos, además de la disciplina y la convivencia en el aula. Vitanzi (2015) anima a aprovechar las múltiples posibilidades que la danza popular ofrece a los estudiantes para reencontrarse con ellos mismos, en otros y con otros.

Las danzas tradicionales han sido utilizadas durante años en la escuela de una forma superficial y descontextualizada, debido ala distancia «entre el mundo de la investigación y el del folclore, la falta de rigor en su recogida y por el aislamiento de su marco natural, la fiesta» (Rizo, 1996, p.73). Además del trabajo psicofísico y motriz, la danza tradicional en el aula debe trabajar aspectos sociales, históricos, culturales y artísticos, en relación a su carácter ritual, festivo, a la construcción de una identidad colectiva en desarrollo, y a la conexión con el entorno en el que se despliega. Para ello, podemos utilizar iconografía e información para contextualizar la danza, el origen, entorno e importancia social, el vestuario, la calidad de movimiento, así como historias, leyendas 0 anécdotas para comprender cómo se organizaba (Rizo, 1996). También será de utilidad la conexión directa con bailarines y músicos profesionales, asistencia a ensayos, actuaciones, museos, festejos, etc., (Haselbach, 1979) y la utilización sin complejos de las nuevas tecnologías para apoyar procesos innovadores de enseñanza-aprendizaje (Gillanders, et al., 2019; Larrinaga, 2007).

Ladanzafolclórica y popular en las instituciones educativas no debe concebirse como manifestación cultural estanca, inmóvil y homogénea, pues su particular na rrativa no puede ser contemplada ni recreada desde la óptica de su contexto original. Su aspecto social, «su narrativa, su movimiento nos antecede y nos trasciende» (Vitanzi, 2015, p.78). Más allá de un repertorio coreográfico del pasado, debemos contemplarla como «un campo de conocimiento, un espacio-tiempo quenos permite narrarnos, contarnos lo que nos pasó y lo que nos pasa hoy, en los nuevos contextos» (Vitanzi, 2015, p.79).

Al mismo tiempo debemos «utilizar y combinar, indistintamente, los diferentes aspectos del Folklore infantil (danza, música, canto, juegos, cuentos... )» (Larrinaga, 2007, p.371), mediante un enfoque interdisciplinar que facilite su conexión con las diversas materias escolares y el entorno natural y social (Rizo, 1996; Sac de Danses, El, 1994). Por último, señalar la necesariasensibilización e implicación de familias, alumnos, instituciones y educadores, promoviendo su participación y comprensión de la dimensión educativa de la danza tradicional (García, 2003; Larrinaga, 2007).

A modo de resumen, en la siguiente tabla, recogemos de forma sintética las ideas generales y aspectos más destacados de cada uno de los documentos analiza dos, en relación con las tres categorías definidas en la estructura inicial.

\section{Conclusiones}

Volviendo a nuestros objetivos de partida en este trabajo de revisión bibliográfica, podemos concluir que:

1.- El número de publicaciones sobre didáctica de la danza y en concreto sobre las danzas folclóricas es escaso y claramente no está actualizado, encontrando pocas referencias a conceptos metodológicos específicos para su enseñanza en las escuelas.

2.- La evolución en aspectos de innovación educativa y renovación pedagógica no puede ser esbozada de una manera clara, pues de todas las referencias consultadas respecto a la última categoría analizada, solo siete se enmarcan en la década entre 2010 y 2020, no siendo, con al guna excepción, la más extensas ni conclusivas. Se hace necesaria la publicación actualizada de nuevos paradigmas en la enseñanza de la danza para la escuela y del repertorio de las danzas folclóricas en particular.

Los procesos de innovación educativa no deben desestimar por completo contenidos educativos y culturalestradicionales, como es el folclore, en pro decambios absolutos. Es decir, las nuevas aportaciones en ma teria de educación deben respetar las manifestaciones del entorno en toda su extensión, y los avances deben de referirse a los procesos metodológicos y didácticos de la enseñanza-aprendizaje. Muchos de los principios contemporáneos educativos, como pueden ser el carácter lúdico y espontáneo, como proceso natural por eda des, están implícitos en los procesos de difusión oral del folclore, proceso vivo en el tiempo (Larraz, 1988).

Como conclusión final, y amodo de discusión, se debe fomentar tanto en la formación inicial del profesorado como en la formación continua de éste, el uso del folclore en todas sus dimensiones, desde el juego tradicional, canciones, retahílas, danzas, como proyección 
Tabla 1.

Síntesis de resultados según categorías.

Autor/año

Larrea, 1950, $1958 \quad$ Folclore y escuela

cotidiana.

政

-Escuela como centro colector y divul gador etnográfico. Maestro como investigador folclórico.

- Carácter transversal y enfoque interdisciplinar: conexión con el resto de materias escolares.

Moya, 1956 - La danza popular como aportación eficaz a la formación integral del niño.

- Conectar la escuela con la cultura tradicional y emocional cotidiana

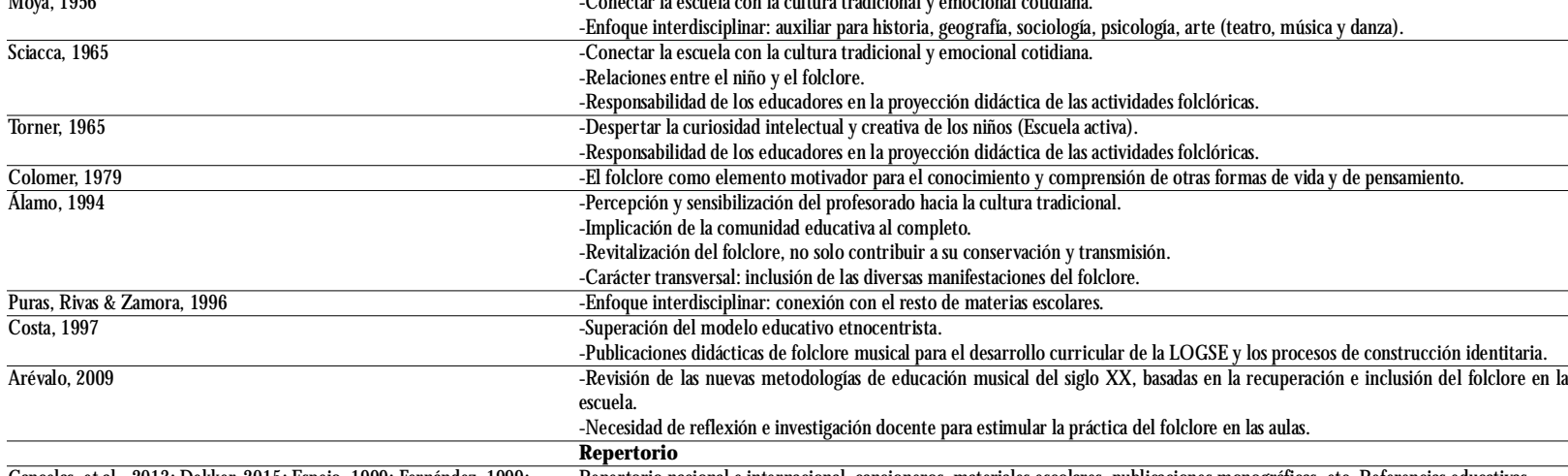

Cancelas, et al., 2013; Dekker, 2015; Espejo, 1999; Fernández, 1999; $\quad$ Repertorio nacional e internacional, cancioneros, materiales escolares, publicaciones monográficas, etc. Referencias educativas

Fuertes, 1993, 2006; Fuertes \& Zamora, 1996; López-lbor \& Maschat,

2006; 0 ssa, et al., 2009; Pedeslán, 2010; Pereira \& Prieto, 2010; Puras, et

al., 1996; Renobell, 2009; Sánchez \& Martín, 2002; Zamora, 1995, 2002

\section{Metodología y escuel}

-Selección de repertorio adecuado

-Importancia del proceso didáctico frente al resultado.

-Aprendizaje lúdico; disfrutar y aprender.

-La música como elemento de introducción a la danza.

-M etodología variada: exploración, improvisación y creación

-Trabajar en círculo (corro), frente a enseñanza frontal.

- Uso de versiones didácticas

- Aprendizaje autónomo y cooperativo.

- Importancia de una contextualización adecuada.

-Música y Danza dentro de una educación estética.

Larraz, 1988, $2003 \quad$-Importancia del proceso didáctico frente al resultado.

-Aprendizaje lúdico; disfrutar y aprender.

-Socialización, comunicación y expresión.

-M etodología variada: expl oración, improvisación y creación.

-Aprendizaje autónomo y cooperativo.

Sac de Danses, EI, $1994 \quad$-Desar rollo integral con metodología bien orientada.

-A prendizaje lúdico; disfrutar y aprender.

-Imitación simultánea.

-La música como elemento de introducción a la danza

-Metodología variada: exploración, improvisación y creación.

-Enfoque interdisciplinar: conexión con el resto de las materias escolares.

Rizo, $1996 \quad$-Aprendizaje lúdico; disfrutar y aprender.

-Enfoque interdisciplinar: conexión con el resto de las materias escolares

-Importancia de una contextualización adecuada.

Muela \& Señor, $1997 \quad$-Importancia del proceso didáctico frente al resultado.

-Aprendizaje lúdico; disfrutar y aprender.

-Socialización comunicación y expresión.

-Aprendizaje autónomo y cooperativo.

Maschat, 2001, 2006, $2013 \quad$ - - Importancián del proceso didáctico frente al resultado.

-Aprendizaje lúdico; disfrutar y aprender.

-Socialización, comunicación y expresión.

-Imitación simultánea.

- Trabajar en círculo (corro), frente a enseñanza frontal.

- La música como elemento de introducción a la danza.

-Metodología variada: exploración, improvisación y creación.

-Música y Danza dentro de una educación estética.

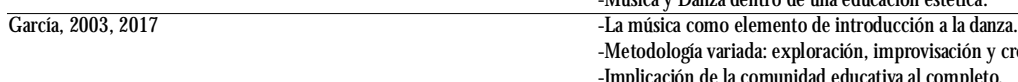

\begin{tabular}{ll}
\hline García, 2003, 2017 & -La música como elemento de introducción a la danza. \\
& -M etodología variada: exploración, improvisación y creación \\
-Implicación de la comunidad educativa al completo.
\end{tabular}

Martín, $2005 \quad$-Canciones-juego para introducir los esquemas coreográficos de las danzas tradicional es.

Larrinaga, $2007 \quad$-Desar rollo integral (actitudes, procedimientos y conocimientos) con metodología bien orientada.

-Importancia de la contextual ización adecuada de las danzas (uso deTICS).

-Enfoque transversal: combinar diferentes manifestaciones del folclore

-Implicación de la comunidad educativa al completo.

Ereño, 2011

-Aprendizaje lúdico. A prendizaje divergente.

Díaz, 2012, 2017 -Importancia del proceso didáctico frente al resultado.

-Introducción de juegos rítmicos.

-La música como elemento de introducción a la danza.

-Metodología variada: exploración, improvisación y creación.

-M ejora de la disciplina y convivencia en el aula.

Vitanzi, 2015 -Importancia del proceso didáctico frente al resultado.

-Socialización, comunicación y expresión.

-Metodología variada: exploración, improvisación y creación.

-Importancia de la contextual ización adecuada: danza tradicional situada en el pasado y en nuestro presente.

Gillanders, Rodríguez \& Eirín, $2019 \quad$-Aprendizaje autónomo.

- Importancia de la contextual ización adecuada de las danzas (uso deTICS).

Fuente: Elaboración propia

-U so de materiales audiovisuales para el aprendizaje de danzas y bailes tradicionales. 
social y cultural, no solo de nuestro entorno, sino también, en un mundo globalizado como el que vivimos, de cualquier manifestación artística y cultural de otros pueblos.

\section{Referencias}

Águila, C. \& López, J. (2019). Cuerpo, corporeidad y educación: una mirada reflexiva desde la Educación Física. Retos. N uevas tendencias en educación física, deporte y recreación, (35), 413-421.

Aguilera, A. (2016). Dansai diversitat metodològica En D. Cañabate, G. Calvet \& M. Bassachs(Ed. ), Dansa a L'Escola. Mapa de bones practiques (pp. 21-24). Publicacions de la Universitat de Girona.

Álamo, L. del (1994). Cultura tradicional y escuela en el ámbito de la Comunidad de Madrid [Manuscrito no publicado]. Madrid: Convocatoria de Premios Nacionales de Investigación e Innovación Educativa. Ministerio de Educa ción y Ciencia.

Arévalo, A. (2009). Importancia del folklore musical como práctica educativa. LEEME. Revista Europea Electrónica de Músca en la Educación, (23), 1-14.

Arias, J., Fernández, B. \& San Emeterio, C. (2020). Construcción y validación de un instrumento para la medida de las actitudes hacia la Expresión Corpora. Retos. Nue vas tendencias en educación física, deporte y recreación, (38), 443-451.

Cancelas, S., Jurado, J. \& Sampil, P. (2013). De roda en roda. Vigo: Editorial Galaxia.

Colomer iVallicrosa, J. (1979). Folklore al'escola. Perspectiva Escolar, (38), 31-35.

Costa, L. (1997). Práctica pedagógica y música tradicional. TRANS-Revista Transcultural de Músca. TRANS Iberia (artículo 7).

Dekker, M. (2015). Danças (en)cantadas e outras nao. VilaVerde: Tradisom

Díaz, A. M. (2012). Intervención en el aula a través de la danza folclórica. Ensayos, Revista dela Facultad deEducación deAlbacete, (27), 101-108.

Díaz, A. M. (2017). La danza tradicional como herramienta de integración social y cultura en laEducación Secunda ria. En B. Martínez \&A. M. Díaz (Coord. ), Danza, género y sociedad (pp. 319-348). Málaga: UAM Editorial.

Díaz, A. M. (2018). Adquisición de conceptos musicales a través de ladanza. DEDiCA. Revista de Educação e H umanidades, (13), 109-119.

Díaz, J. \& Porro, C. (2007). Los Bailes Ser y estar en Castilla León. [CD]. U rueña,Valladolid: Fundación Joaquín Díaz. Díaz, J. \& Porro, C. (2008). Las Danzas: Ser y estar en Castilla
León. [CD]. U rueña, Valladolid: Fundación Joaquín Díaz. Domínguez, M. (2012). 0 pinión de los docentes de música sobre la praxis del movimiento y la danza en Educación Primaria. En P. Miralles\& A. B. Mirete (Eds.), La formación del profesorado en Educación Infantil y Educación Primaria (pp. 143-149). Murcia: Servicio de publicaciones de la Universidad de Murcia.

Ereño, C. (2 de septiembre de 2011). El proceso de enseñanza aprendizaje en la danza tradicional: Alternativas metodológicas. Reflexiones desde la propia práctica. Euskonews. Recuperado de: http:/ / www. euskonews eus/ 0590zbk/ gaia59003eshtml

Espejo, A. (1999). Danzas de Madrid en la escuela. Madrid: Editorial CCS.

Fernandez, M. (1999). Taller dedanzas y coreografías: Educación infantil y primaria. Madrid: CCS.

Fontán, A. (2019). Entre la danza folclórica y su enseñanza: algo más que un asunto de codificación. En Jornadas de Investigación. 5 a Edición CFE [se] expone. Montevideo, U ruguay: Consejo deFormación en Educación (CFE-ANEP).

Fuertes, M. (1993). Danzas de animación. Madrid: San Pablo, D.L.

Fuertes, M. (2006). Taller de danzas de animación. Madrid: CCS.

Fuertes, M. \& Zamora, A. (1996). Danzas y formación rítmico musical. Madrid: San Pablo, D.L.

García, A. R. (2003). Todos Bailamos. Proyecto del C.P. Virgen del Carmen de Madrid. Orff-España, (6), 15-18.

Gillanders, C. , Rodríguez, J. E. \& Eirín, R. (2019). Impacto del uso de materiales audiovisuales para el aprendizaje de danzas y bailes tradicionales en la formación de estudiantes universitarios. RELATEC, Revista Latinoamericana deTecnología Educativa, 18(2), 101-115.

Haselbach, B. (1979). Didácticadeladanza. EnB. Haselbach \& H. Regner (Eds), M úsica y danza para el niño (pp. 6578). Madrid: Instituto alemán.

Haselbach, B. (2011). Reflexiones sobrelos aspectos educa tivos de la danza en el O rff-Schulwerk En B. Haselbach (Ed.), Textos sobre Teoría y Práctica del Orff-Schulwerk (pp. 71-78). Vitoria-Gasteiz: AgrupArte. (1a edición 1984).

Herrera, S. (2000). Ver la música, escuchar el movimiento. LEEME (Revista Electrónica Europea de Música en la Educadión), (5), 1-4.

Lago, P. \& Espejo, A. (2007). El movimiento y la danza: su importancia dentro del curriculum de primaria. Educación y futuro: revista de investigación aplicada y experiencias educativas, (17), 149-164.

Larraz, A. (1988). A plicació educativai escolar de las Danses Folklòriques Apunts (11-12), 42-46.

Larraz,A. (2003). Las danzascolectivas en la educación física 
escolar. En G. Sánchez, B. Tabernero, F.J. Corterón, C. Llanos\& B. Learreta (Coord. ), Actas del Congreso Internacional de Expresión Corporal y Educación: Expresión, Creatividad y M ovimiento (pp. 191-196). Salamanca: Amaru Ediciones.

Larrea, A. de (1950). El Folklorey la Escuela: Ensayo de una Didáctica Folklórica. Bordón. Revista de pedagogía, (15), 29-34.

Larrea, A. de (1958). El Folklore y la Escuela: Ensayo de una Didáctica Folklórica. Madrid: Consejo Superior de Investigaciones Científicas. Instituto «San José de Calasanz» de Pedagogía.

Larrinaga, J. (2007). Folklore y educación: hacia una nueva metodología. Jentilbaratz, (9), 361-374.

López, M. \& Vicente, G. (2019). Movimiento y danza en Educación Secundaria. ¿Un fraude curricular o un currículo fraudulento? Revista Interuniversitaria de Formación del Profesorado, 94(33.3), 213-234.

López, N, López, A. M. \&Vicente, G. (2020). La danza en Educación Física: análisis de los currículos autonómicos españoles de Educación Primaria. Retos. Nuevastendencias en educación físca, deportey recreación, (38), 517-522.

López-Ibor, S. \& M aschat, V. (2006). iQuien canta su mal es panta! Songs, Games and Dances from Latinamerica. Schott Musik International.

Martín, M. J. (2005). Del movimiento a la danza en la educación musical. Educatio, (23), 125-139.

Maschat, V. (2001). It es auch tradierter Tanz, hat er doch Methode. Orff-Schul werk Informationen, (67), 46-49.

Maschat, V. (2006). El efecto social y emocional de la danza coral. Orff-España, (9), 7-9.

Maschat, V. (2013). ¿Q ué bailamos hoy? Formas básicas de danza. Orff-España, (14), 7-10.

Matos-Duarte, M., Smith, E. \& Muñoz, A. (2020). Danzas folclóricas: una forma de aprender y educar desde la perspectiva sociocultura. Retos Nuevastendencias en Educación Físca, Deportesy Recreación, (38), 739-744.

Moya, I. (1956). Didáctica del folklore. BuenosAires: Editoria Schapire.

Muela, F. J. \& Señor, D. M. (1997). Danzas del Mundo. Eufonía. Didáctica dela Música, (6), 45-52.

0 ssa, S. de la, Iglesias, X., Fügedi, J. \& Parga, J. (2009). Aś fan os bailadores... Repertorio de iniciación aos bailes edanzas de Galicia. Pontevedra: DosAcordes.

Patricio, H. (2018). El Sac de Danses: històriai llegat d'una experiènciadedansaal'escola. Tempsd'Educació, (54), 111125.

Pedeslán (2010). Na punta do pé. Pontevedra: Kalandraka.

Peña, V. J., \&Vicente, G. (2019). Danza en educación infan-

til: opinión de los docentes. Retos Nuevas tendencias en educación físca, deportey recreación, (36), 239-244.

Pereira, M. \& Prieto, M. (2010). Zampadanzas del Mundo. Pontevedra: Cumio.

Prados, M. E. (2020). Pensar el cuerpo. De la expresión corporal a la conciencia expresivocorporal, un camino creativo narrativo en la formación inicial del profesora do. Retos Nuevas tendencias en educación física, deporte y re creación, (37), 643-651.

Puras, J. A., Rivas, M. T. \& Zamora, A. (1996). Didáctica del folklore M elodías tradicionales para jugar y bailar. Valladolid: Castilla Ediciones.

Renobell, G. (2009). Todo lo que hay que saber para bailar en la escuela: propuestas de danza-movimiento y expresión corporal para la etapa de educación primaria (6 a 12 años). Barcelona: Inde.

Ríos, P. (2017). El movimiento y la danza en la educación musical. En R. Cremades (Coord.), Didáctica de la Educación Muscal en Primaria (pp. 99-128). Madrid: Paraninfo.

Rizo, G. (1996). La enseñanza de los bailes y las danzas tra dicionales en la escuela: un enfoque interdisciplinar. Eufonía: Didáctica dela Música, (3), 73-84.

Sac deDanses, El (1994). El galop: Dansascatalanesi jocsdansats. Barcelona: Alta Fulla.

Sanchez, J. \& M artin, J. (2002). Bailesdel mundo: una propuesta de bailes populares para educación primaria. Barcelona: Paidotribo.

Sciacca, G. M. (1965). El niño y el folklore. Buenos Aires: Universitaria de Buenos Aires.

Torner, E. M. (1965). El folklore en la escuela. BuenosAires: Losada.

Vicente, G., M ondéjar, A. \& Díaz, A. (2014). La danza y músicatradicional en el aulade educación primaria: opinión del alumnado. EnC.J. Gómez\&A. Escarbaja (Eds). Calidad e Innovación en Educación Primaria (pp. 433-445). Murcia: Ediciones Universidad de Murcia.

Vitanzi, M. I. (2015). Danzafolklóricay popular en laeduca ción común y obligatoria. En M. Mardones (Coord.), CuadernosdeEducación artística: danza (pp. 71-88). Ciudad Autónoma de BuenosAires: Ministerio de Educación.

Zamora, A. (1995). Danzas del mundo. Madrid: CCS.

Zamora, A. (2002). Cantos para jugar y bailar. En J. M. Beltran, J. Díaz, A. Pelegrín \& A. Zamora (Coord.), Folklore muscal infantil (pp. 145-168). Madrid: Akal.

\section{(Footnotes)}

${ }^{1}$ Se utilizará el masculino niño, maestro, educador, autor, etc. , por razones de economía del lenguaje, pero en ningún momento supondrá ninguna distinción por género. 